\title{
Evidence for Pacific-modulated precipitation variability during the late Holocene from the southwestern USA
}

\author{
Jessica B. T. Rasmussen, ${ }^{1}$ Victor J. Polyak, ${ }^{1}$ and Yemane Asmerom ${ }^{1}$ \\ Received 12 January 2006; revised 2 March 2006; accepted 9 March 2006; published 18 April 2006.
}

[1] The mechanisms driving late Holocene drought cycles in the western United States are not well known due to the general scarcity of long-term, high-resolution, absolutely dateable proxies for precipitation in continental interiors. Here we show that late Holocene precipitation variability in the southwestern United States has been caused by changes in the Pacific Ocean. We present a stalagmite-based, annually resolved moisture record that indicates large shifts from pluvial to drought conditions alternating with periods of dampened, near-average precipitation over the last 3000 years. Significant spectral peaks at decadal-scale ( 20-50, 70-80 year) frequencies likely correspond to modern frequencies of the Pacific Decadal Oscillation or a low-frequency component of the El Niño-Southern Oscillation, and are dominant during episodes of large precipitation shifts. Overall pluvial conditions punctuated by severe droughts may have challenged the adaptive capacities of emerging agrarian communities of ancestral Americans. Citation: Rasmussen, J. B. T., V. J. Polyak, and Y. Asmerom (2006), Evidence for Pacific-modulated precipitation variability during the late Holocene from the southwestern USA, Geophys. Res. Lett., 33, L08701, doi:10.1029/ 2006 GL025714.

\section{Introduction}

[2] The effects of drought can be devastating in climatically marginal regions such as northern China [Menon et al., 2002] and the Sahel belt in Africa [Nicholson et al., 1998]. Paleoclimate evidence suggests changes in precipitation over the last 10,000 years had a profound effect on the cultural evolution of ancestral Americans in the southwestern United States (SW), particularly on hunters and gatherers in the middle Holocene [Meltzer, 1991] and early agrarian communities in the late Holocene [Polyak and Asmerom, 2001]. Given the ecological effects of drought cycles around the world, it is imperative that we understand the mechanisms behind periods of dramatic shifts in relative moisture during the late Holocene.

[3] Decadal climate oscillations in the north Pacific over the last century are well-documented [Latif and Barnett, 1994; Mantua et al., 1997; Nakamura et al., 1997], and evidenced by tree-ring reconstructions from the western U.S. [Biondi et al., 2001; D'Arrigo et al., 2001] to have occurred over the last few hundred years, suggesting Pacific Decadal Oscillation (PDO)-type variability is a possible candidate for driving drought cycles in the region. Similarly,

\footnotetext{
${ }^{1}$ Department of Earth and Planetary Sciences, University of New Mexico, Albuquerque, New Mexico, USA.
}

Copyright 2006 by the American Geophysical Union. 0094-8276/06/2006GL025714\$05.00
El Niño-Southern Oscillation (ENSO)-type mechanisms are suggested as a possible cause for elevated aridity in the western U.S. from A.D. 900-1300 [Cook et al., 2004a], a period overlapping what may have been an interval of cool and/or dry mean climate conditions in the central tropical Pacific, consistent with a La Niña-like state [Cobb et al., 2003]. However the persistence of PDO- and ENSO-type variability during the late Holocene and its role in modulating precipitation is not well known, in part due to the scarcity of high-resolution, absolutely dateable proxies for precipitation in continental interiors. It has been demonstrated that some speleothems from the Guadalupe Mountains in southeastern New Mexico are annually banded, and variations in band thickness and mineralogy can be used as a record of regional relative moisture [Asmerom and Polyak, 2004]. Here we present results from a speleothem-based, annually resolved record of moisture for the SW over the last 3000 years.

\section{Results}

[4] In the modern relationship between western U.S. precipitation and the interannual to decadal climate oscillations associated with ENSO and PDO, positive PDO phases and El Niño ENSO phases correspond to increased winter precipitation in the SW [Mantua et al., 1997; McCabe and Dettinger, 1999]. We compared the precipitation record for our study region (New Mexico Climate Division 07, hereafter NMCD07) to the Southern Oscillation Index (SOI) and PDO Index and measured correlations of $r=-0.44$ (A.D. 1895-2002), and $r=+0.50$ (A.D. 1900-2002), respectively (see auxiliary material ${ }^{1}$ Figure S1

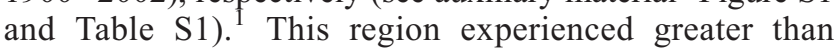
average precipitation during positive PDO phases (19251946, 1977-mid 1990s), and less than average precipitation during a negative phase (1947-1976).

[5] An actively growing stalagmite top (BC7) was collected from Carlsbad Cavern in the Guadalupe Mountains to compare stalagmite growth with the instrumental precipitation record (NMCD07) during the last century. The stalagmite shows a positive correlation $(r=0.29)$ to the precipitation record from A.D. 1939-2002, with thicker (thinner) stalagmite bands corresponding to wetter (drier) periods. For the shorter time period from 1939-1992, when the tree-ring record for the Guadalupe Mountains terminates, the correlation between the precipitation and stalagmite records $(\mathrm{r}=0.45)$ is comparable to the correlation $(\mathrm{r}=$ 0.26 ) between the precipitation and tree-ring record (Figure $\mathrm{S} 2)$. Data from stalagmite $\mathrm{BC} 2$ was compared to the

\footnotetext{
${ }^{1}$ Auxiliary material is available at $\mathrm{ftp} / / \mathrm{ftp}$.agu.org/apend/gl/ $2006 \mathrm{gl025714.}$
} 


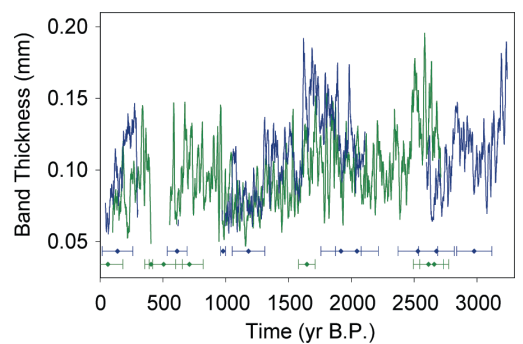

Figure 1. Stalagmite records $\mathrm{BC} 2$ (green) and $\mathrm{HC} 1$ (blue), 10 -year moving average applied. U-Th dates for $\mathrm{HC} 1$ and $\mathrm{BC} 2$ are shown in blue and green diamonds, respectively. Correlation between stalagmites is $\mathrm{r}=0.54$ for the overlapping segments from $991-2113$ yr B.P.

Guadalupe Mountains tree-ring record for the few hundred years preceding the instrumental record (Figure S3), and also shows positive correlations of $r=0.23$ from A.D. $1700-$ 1900 , and $\mathrm{r}=0.45$ for the shorter period from $1750-1850$.

[6] Our moisture record comes from two columnar stalagmites collected from Carlsbad Cavern (BC2) and Hidden Cave $(\mathrm{HC} 1)$ in the Guadalupe Mountains. Limited data from $\mathrm{BC} 2$ was presented in previous work [Polyak and Asmerom, 2001]; here we include the precisely measured, annually resolved record tied to a more robust chronology, and compare it to a second contemporaneous stalagmite record, HC1. Approximately eight U-Th dates were obtained by TIMS for each stalagmite (Figure 1 and Tables S2 and S3); band thickness growth rate was within error of the U-series growth rate for each sample (Table S4), confirming that banding is annual. The result is a record of stalagmite band thickness variations for the last 3245 years, calibrated at the interannual- to decadal-scale to the instrumental precipitation and tree ring records. When compared to one another, the two stalagmites show similar variations in band thickness (Figure 1).

[7] While there is a good visible match between these stalagmites, direct year-to-year correlation is relatively weak. Although banding is annual in each case, it is difficult to match year to year from occasional irregularities. Bandpass analyses of the raw records from 991-2113 yr B.P. shows higher correlation at the decadal $(10-80 \mathrm{yr})$ and centennial $(80-300 \mathrm{yr})$ time-scales $(\mathrm{r}=0.20$ and $\mathrm{r}=0.50$, respectively) compared to the interannual $(2-8 \mathrm{yr})$ correlation $(r=0.10)$. However, correlation of banding with precipitation and tree-ring records gives merit to the internal annual-scale variability preserved in the stalagmites. Both records, $\mathrm{BC} 2$ and $\mathrm{HC} 1$, suggest periods of dramatic precipitation variability over the last 3000 years, exhibiting large shifts unlike anything seen in the modern record. We conducted time series analyses on each record, selecting contemporaneous segments with no apparent hiatuses to avoid problems with missing and unevenly spaced data. Long-term changes in mean bandwidth were removed with a lowess estimator to isolate high-frequency variability, and the residuals checked for periodicity using the autocorrelation function and raw periodograms. Both methods showed an underlying periodic structure to the data (Figure S4).

[8] Because of the large sample size for this segment $(\mathrm{N}=1123)$, visual comparison of the high-frequency signals is difficult (Figure S5); to evaluate common periodicities in the two stalagmites, contemporaneous segments were also tested for significant narrowband or harmonic signals using multiple-taper method (MTM) spectral analysis. MTM analyses [Dettinger et al., 1995; Ghil et al., 2002] show significant (above $90 \%$ confidence) peaks at interannual $(2-5 \mathrm{yr})$, decadal $(\sim 20-50,70-80 \mathrm{yr})$ and centennial (114-128 yr) frequencies in each record (Figure 2). Given the modern precipitation regime, the interannual and decadal frequencies are likely analogous to modern ENSO and PDO frequencies. The decadal variability likely corresponds to the PDO, which has modern frequencies of $15-25$ years and 50-70 years [Minobe, 1997, 1999], or to a low-frequency component of ENSO. While the periodicity of modern ENSO events is approximately $2-7$ years, decadal variability in ENSO also has been observed [Cane, 2005], making it difficult to separate ENSO from PDO in the stalagmite data presented here. The dominant centennial-scale peak between 114 and 128 years could be a higher order PDO harmonic, or more likely reflect (within the errors of the spectral windows) the 126 solar peak [Stuiver and Braziunas, 1993], which has been proposed as contributing to climate variability in the SW [Asmerom et al., 2004; also Solar forcing of Holocene climate: New insights from a speleothem record, southwestern United States, submitted to Geology, 2006, hereinafter referred to as Asmerom et al., submitted manuscript, 2006].

[9] Wavelet analysis [Torrence and Compo, 1998] also shows common behavior in the two stalagmites (Figure 3), with increased decadal variability around $1400-1600$, $1700-1900$ yr B.P. in $\mathrm{BC} 2$, and $\sim 1300,1600$, and 1800 yr B.P. in HC1. Both stalagmites show increased

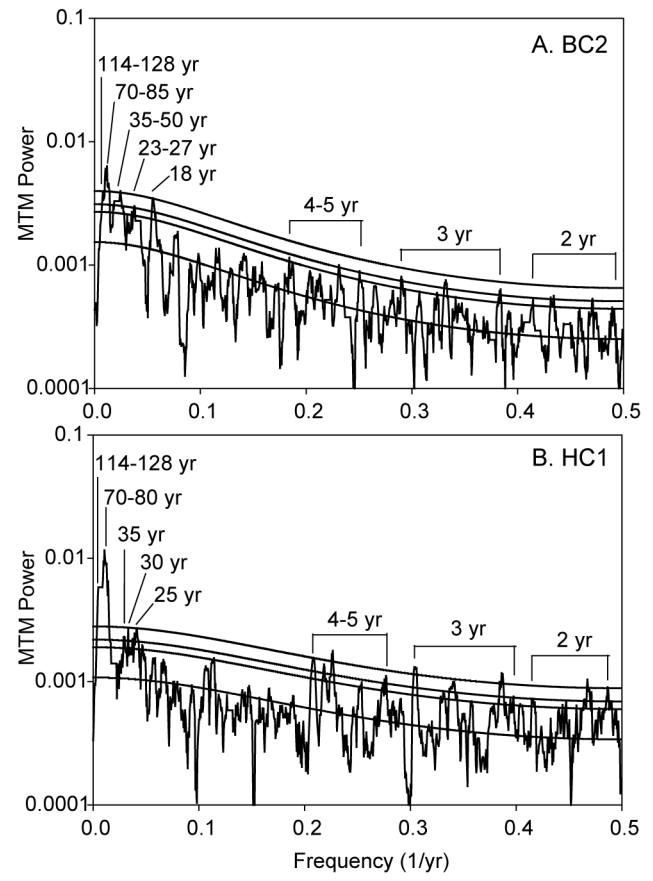

Figure 2. MTM results for (a) $\mathrm{BC} 2$ and (b) $\mathrm{HC} 1$ from 991-2113 yr B.P. Solid black curves denote (from top to bottom) the $99 \%, 95 \%, 90 \%$ confidence and median red noise levels. MTM analyses were performed using the SSAMTM Toolkit available at URL:http://www.atmos.ucla.edu/ tcd/ssa/. $\mathrm{N}=1123$ for $\mathrm{BC} 2$ and $\mathrm{HC} 1$. Parameters $\mathrm{p}=3, \mathrm{~K}=$ 5 , smoothing $=0.1$, and a null hypothesis of "red noise" was used in the analyses. 

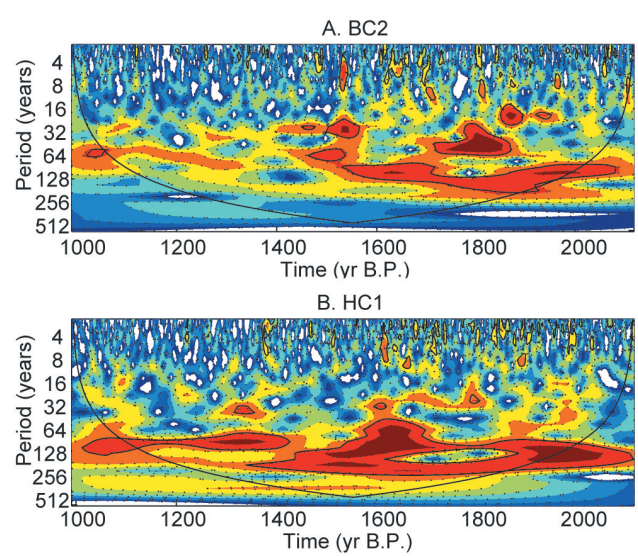

Figure 3. Wavelet analysis for (a) $\mathrm{BC} 2$ and (b) $\mathrm{HC} 1$ from 991-2113 yr B.P. Solid black line indicates the 95\% confidence level (power significance); more intense colors indicate higher power. Wavelet software was provided by C. Torrence and G. Compo, available at URL: http://paos.colorado.edu/research/wavelets/. $\mathrm{N}=1123$ for $\mathrm{BC} 2$ and $\mathrm{HC} 1$. The time series were padded with zeros, and parameters $\mathrm{dj}=$ $0.25, \mathrm{~s} 0=2, \mathrm{j} 1=36$ and mother wavelet $=$ Morlet. Significance levels were set at $95 \%$, and a red noise background was estimated from the alpha parameter described in [Torrence and Compo, 1998].

interannual and centennial variability between 1500 2000 yr B.P., corresponding to overall thicker stalagmite bands. When evaluated over the length of the full records (Figure S6), the decadal variability clusters around largemagnitude shifts in band thickness, including not only the thickest bands in the record, but also the thinnest, such as major droughts occurring around 2500, 2000-1800, 1650, $1550,1400,1000$, and $700 \mathrm{yr}$ B.P. The interval from $1100-$ 1400 yr B.P. in both stalagmites exhibits little decadal variability, and corresponds to more stable, smaller-magnitude shifts and thinner stalagmite bands. The variance within the decadal $(10-80 \mathrm{yr})$ frequency band reflects the same pattern, with increased variance corresponding to periods of large changes in band thickness (Figure S7).

\section{Discussion}

[10] The stalagmite data presented here suggest pervasive decadal variability in effective moisture over the last 3000 years. Dramatic changes in precipitation over relatively short time periods are indicated by hiatuses in stalagmite growth around $400-550$ and 1000 yr B.P., and large-scale shifts in band thickness around $600-800,950-1100,1600$, $1800-2000,2400-2800$, and $3050-3200 \mathrm{yr}$ B.P. Some of these intervals correspond to major droughts around 700 and $400 \mathrm{yr}$ B.P. evidenced by tree-ring records for the SW [Grissino-Mayer, 1997; Stahle et al., 2000]. Both the major droughts and wet periods coincide with intervals of enhanced decadal variability, suggesting a more active PDO/ ENSO system (or stronger teleconnection to these oscillations) is responsible for modulating major drought and pluvial events. For example, the period from $1100-700 \mathrm{yr}$ B.P. (A.D. 900-1300) includes severe drought events, consistent with tree-ring data for the western U.S. [Cook et al., 2004a]; but more noticeable are the rapid largeamplitude shifts from wet to dry conditions, exemplified around $1000 \mathrm{yr}$ B.P. The coincidence of dramatic shifts with stronger decadal variability suggests a more active $\mathrm{PDO} /$ ENSO system, consistent with the idea of more frequent $\mathrm{La}$ Niña events and/or negative PDO phases causing elevated aridity in the region during this time. Comparison of our stalagmite data to the tree-ring based summer drought reconstruction for the study region [Cook et al., 2004b] and the Peruvian El Niño flood record [Rein et al., 2004] provides additional support for this relationship between large-scale precipitation variability and the PDO/ENSO system (Figure 4). While the drought index is a record of summer precipitation, the stalagmite data is sensitive to winter precipitation variability, which may account for some of the differences between these records. However, both the tree-ring and stalagmite records show increased precipitation variability from $1900-1250$ and $800-500$ yr B.P., with major droughts around 1900,1650,1550, coinciding with increased El Niño flooding events. Conversely, the stalagmite record shows dampened precipitation variability and overall drier conditions from $800-1250$ yr B.P., coinciding with reduced El Niño flooding.

[11] The salient feature in our record is alternating intervals of extreme drought and pluvial conditions during overall moist periods, such as $3200-1500$ yr B.P., which was wetter and more variable than the most recent 1500 years. This oscillation between extremes over relatively short time periods would have had a greater impact on human and ecological adaptation than alternating periods of extended pluvial and drought conditions. The arrival of agrarian communities in the SW occurred at the beginning

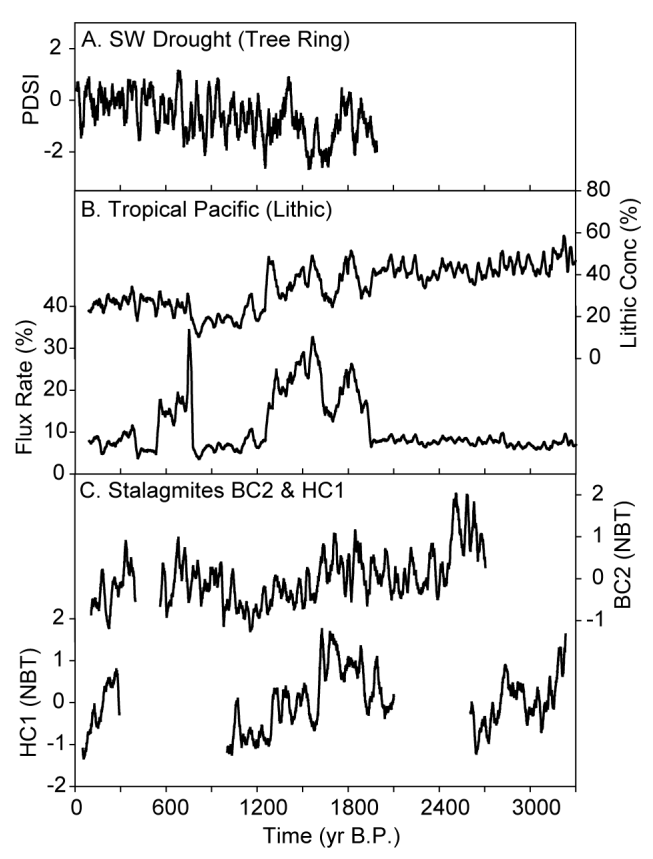

Figure 4. (a) Tree-ring based summer drought reconstruction for the study region from PDSI grid point $105.0 \mathrm{~W}$, $32.5 \mathrm{~N}$ [Cook et al., 2004b]; (b) marine sediment-based El Niño flood record from Peru plotted as lithic concentration and flux rate [Rein et al., 2004]; and (c) normalized band thickness (NBT) records for stalagmites $\mathrm{BC} 2$ and $\mathrm{HC} 1$. 
of a lengthy pluvial period around $3000 \mathrm{yr}$ B.P. [Polyak and Asmerom, 2001]; extreme drought intervals within overall moist periods may be a possible cause for wide spread dwelling abandonment or adjustment during the pueblo periods throughout the SW. The persistence of PDO/ ENSO-type modulation of precipitation during the late Holocene suggests it is a permanent feature of SW climate.

[12] While our data do not allow us to address the cause of PDO/ENSO variability, we can make some inferences. Modern precipitation in our study region (NMCD07) is negatively correlated $(\mathrm{r}=-0.45)$ to regional precipitation in China (Figure S8), suggesting a relationship between the two climate regimes that is likely connected to the Pacific Ocean. Although El Niño events and positive phases of the PDO correspond to wetter conditions in our study region, the relationship between ENSO and the Asian monsoon is less apparent. However, following an El Niño event the monsoon is typically weakened and the region characterized by drought [Chan and Zhou, 2005]. Based on the seesaw response of North American and Asian Monsoons and the significant correlation between SW Holocene climate and solar variability, Asmerom et al. [2004, also submitted manuscript, 2006] have proposed solar modulation of Holocene PDO/ENSO variability. The effects of global warming on the PDO/ENSO system and SW and Asian climate regimes should be of great concern, given the potential for temperature perturbations greater than those resulting from solar variability alone.

[13] Acknowledgments. $\mathrm{BC} 2$ and $\mathrm{BC} 7$ were collected from Carlsbad Caverns National Park, permit and support through D. Pate and S. Allison, and $\mathrm{HC} 1$ from Lincoln National Forest, permit through R. Turner and K. Glover. We thank P. Provencio and S. Bono for field assistance and G. Huerta for a constructive review of the pre-submittal version of the manuscript. This material is based upon work supported by an NSF Graduate Research Fellowship (J.T.R), and NSF grant ATM-0214333 (V.J.P., Y.A.)

\section{References}

Asmerom, Y., and V. J. Polyak (2004), Comment on "A test of annual resolution in stalagmites using tree rings," Quat. Res., 61, 119-121.

Asmerom, Y., et al. (2004), Evidence for a direct link between solar variability and Holocene climate in the Southwest, Eos Trans. AGU, 85(47), Fall Meeting Suppl., Abstract GC51D-1093.

Biondi, F., et al. (2001), North Pacific decadal climate variability since 1661, J. Clim., 14, 5-10.

Cane, M. A. (2005), The evolution of El Niño, past and future, Earth Planet. Sci. Lett., 230, 227-240.
Chan, J. C. L., and W. Zhou (2005), PDO, ENSO and the early summer monsoon rainfall over south China, Geophys. Res. Lett., 32, L08810, doi:10.1029/2004GL022015.

Cook, E. R., et al. (2004a), Long-term aridity changes in the western United States, Science, 306, 1015-1018.

Cook, E. R., et al. (2004b), North American summer PDSI reconstructions, http:/www.ncdc.noaa.gov/paleo/datalist.html, World Data Cent. for Paleoclimatology, Boulder, Colo.

Cobb, K. M., et al. (2003), El Niño/Southern Oscillation and tropical Pacific climate during the last millennium, Nature, 424, 271-276.

D'Arrigo, R. D., et al. (2001), Tree-ring estimates of Pacific decadal climate variability, Clim. Dyn., 18, 219-224.

Dettinger, M. D., et al. (1995), Software expedites singular-spectrum analysis of noisy time series, Eos Trans. AGU, 76(2), 12, 14, 21.

Ghil, M., et al. (2002), Advanced spectral methods for climatic time series, Rev. Geophys., 40(1), 1003, doi:10.1029/2000RG000092.

Grissino-Mayer, H. D. (1997), The rare, old-aged conifers of El Malpais: Their role in understanding climatic change in the American Southwest, New Mex. Bur. Mines Miner. Resour. Bull., 156, 155-161.

Latif, M., and T. Barnett (1994), Causes of decadal climate variability over the North Pacific and North America, Science, 266, 634-637.

Mantua, N., et al. (1997), A Pacific interdecadal climate oscillation with impacts on salmon production, Bull. Am. Meteorol. Soc., 78, 10691079 .

McCabe, G. J., and M. D. Dettinger (1999), Decadal variations in the strength of ENSO teleconnections with precipitation in the western United States, Int. J. Climatol., 19, 1399-1410.

Meltzer, D. J. (1991), Altithermal archealogy and paleoecology at Mustang Springs, on the southern High Planis of Texas, Am. Antiq., 56, 236-267.

Menon, S., et al. (2002), Climate effects of black carbon aerosols in China and India, Science, 297, 2250-2253

Minobe, S. (1997), A 50-70 year climatic oscillation over the North Pacific and North America, Geophys. Res. Lett., 24, 683-686.

Minobe, S. (1999), Resonance in bidecadal and pentadecadal climate oscillations over the North Pacific: Role in climatic regime shifts, Geophys. Res. Lett., 26, 855-858.

Nakamura, H., et al. (1997), Decadal climate variability in the North Pacific during the recent decades, Bull. Am. Meteorol. Soc., 78, 2215-2225.

Nicholson, S. E., et al. (1998), Desertification, drought, and surface vegetation: An example from the West African Sahel, Bull. Am. Meteorol. Soc., $79,815-829$.

Polyak, V. J., and Y. Asmerom (2001), Late Holocene climate and cultural changes in the southwestern United States, Science, 294, 148-151.

Rein, B., et al. (2004), A major Holocene ENSO anomaly during the Medieval period, Geophys. Res. Lett., 31, L17211, doi:10.1029/ 2004GL020161.

Stahle, D. W., et al. (2000), Tree-ring data document 16 th century megadrought over North America, Eos Trans. AGU, 81(12), 121, 125.

Stuiver, M., and T. F. Braziunas (1993), Sun, ocean climate and atmospheric ${ }^{14} \mathrm{CO}_{2}$ : An evaluation of causal and spectral relationships, Holocene, 3, 289-305.

Torrence, C., and G. P. Compo (1998), A practical guide to wavelet analysis, Bull. Am. Meteorol. Soc., 79, 61-78.

Y. Asmerom, V. J. Polyak, and J. B. T. Rasmussen, Department of Earth and Planetary Sciences, MSCO3-2040, 1 University of New Mexico, Albuquerque, New Mexico 87131-0001, USA. (jbtoledo@unm.edu) 